\title{
Endocrine Treatment - ‘Old-Fashioned' Therapy Becoming Redundant in an Era of Molecular Medicine?
}

\author{
Per Eystein Lønning \\ Section for Oncology, Institute of Medicine, University of Bergen, Norway
}

\section{Introduction}

For more than a century, endocrine therapy has been recognized as an effective, but palliative, treatment option for advanced breast cancer. Over the last 2 decades, 2 important observations have dramatically changed this conceptual view. The first observation was the finding that tamoxifen, but also ovarian ablation, causes sustainable relapse-free and overall survival benefits in the adjuvant setting $[1,2]$. The second finding relates to the potential for improvement. While for decades, randomized studies comparing different endocrine regimens had revealed 'no significant difference' between the different endocrine treatment options regarding efficacy, third-generation aromatase inhibitors improved time to progression in metastatic disease [3] but also relapse-free survival in the adjuvant setting [4-8] compared to tamoxifen. In addition, studies have challenged the need for chemotherapy to hormone receptor-positive premenopausal low-risk patients, suggesting many patients may be well treated with endocrine therapy alone $[9,10]$, omitting the toxicity of chemotherapy. Ongoing studies are addressing important topics in adjuvant therapy. What is the optimal use of aromatase inhibitors (tamoxifen upfront versus aromatase inhibitor monotherapy, optimal duration of treatment)? And how may we improve treatment for premenopausal women? Tamoxifen and an luteinizing hormone-releasing hormone (LHRH) analogue administered in concert has been shown to improve response rate compared to monotherapy in metastatic disease $[11,12]$, but we lack evidence whether this improves outcome compared to tamoxifen alone in the adjuvant setting.

\section{Endocrine Therapy and Resistance in Estrogen Receptor-Positive Breast Cancer}

The cause of resistance to endocrine therapy among estrogen receptor (ER)-positive breast cancers is poorly understood. While experimental evidence suggests that constitutive activation of growth factor mechanisms may play a role [13,14], so far we lack evidence linking these mechanisms to resistance in vivo. Notably, with exception of adding trastuzumab to anastrozole in patients with ER-positive HER-2-overexpressing tumors [15], inhibiting growth factors in concert with aromatase inhibition so far has not improved outcome [16]. Notably, endocrine therapy is as effective for treating ER-positive premenopausal as well as postmenopausal breast cancer. Ovarian suppression (surgically, radiologically, or with use of an LHRH analogue) reducing premenopausal estradiol to postmenopausal levels has dramatic anti-tumor effects [2]. On the other hand, postmenopausal women experience tumor growth stimulation by these low estradiol levels, subsequently to achieving anti-tumor effects by further suppression through treatment with aromatase inhibitors. How may we explain this observation? Laboratory experiments have revealed ER-positive tumor cells may 'adapt' to long-term estrogen deprivation (LTED) by acquiring estrogen 'hypersensitivity' [17]. Thus, these cells achieve a condition of estradiol hypersensitivity, obtaining maximal growth stimulation with an estradiol concentration $1 / 1,000$ to $1 / 10,000$, the concentration required for wild type cells. This raises the intriguing question whether hormone-sensitive cells may adapt their sensitivity to the local estrogen environment in vivo.

In addition, these studies revealed estradiol growth stimulation in vitro to follow a 'bell-shaped' curve; estradiol at high concentrations inhibited cell growth [17, 18]. Estrogens in pharmacological doses were used for endocrine therapy prior to implementation of contemporary standards [19]. While

\section{KARGER}

Fax +497614520714

Information@Karger.de

www.karger.com
(C) 2008 S. Karger GmbH, Freiburg

Accessible online at:

www.karger.com/brc
Prof. Dr. med. Per Eystein Lønning

Section for Oncology, Institute of Medicine

University of Bergen, Haukeland Universitetssykehus

5021 Bergen, Norway

Tel. +47 55 97-5000, Fax -2046

per.lonning@helse-bergen.no 
tamoxifen and estrogens revealed similar anti-tumor efficacy [20], side effects were more profound with estrogens. Combining evidence from in vitro studies with clinical data, we postulated tumors developing acquired resistance on aromatase inhibitors could be sensitive to treatment with estrogens in pharmacological doses. Among 32 heavily exposed (median 4 previous regimens) tumors, 10 achieved an objective response, with another 2 tumors obtaining stable disease for $>6$ months [21]. This finding suggests that i) tumors relapsing even on potent third-generation aromatase inhibitors may still be hormonel sensitive, and ii) tumor cells may adapt their 'sensitivity window' to the hormonal environment also in vivo.

\section{Future Outlook}

There are several ways forward. First, there is a need for basic research and, in particular, translational research, to sort out the mechanisms of acquired endocrine resistance in ER-positive tumors. Trials evaluating targeted therapy in concert with endocrine manipulation are highly warranted; however, patient selection should be based on biomarkers suggesting sensitivity to a particular treatment option; alternatively, these trials should include systematic tissue sampling, allowing for retrospective identification of predictive markers for subsequent testing in a prospective setting [22].

However, there is also a need to concentrate on optimal use of endocrine therapy per se. The ATAC study revealed tamoxifen and estrogen suppression with anastrozole in concert to be inferior to anastrozole monotherapy. The situation may be different for premenopausal women. As mentioned above, the use of tamoxifen and an LHRH analogue in concert has been shown to moderately improve outcome compared to monotherapy in premenopausal metastatic breast cancer. On the other hand, the finding that potent third-generation aromatase inhibitors improve outcome, contrasting the less potent first- and second-generation compounds, further underlines the benefit of maximal estrogen suppression [23]. Now, these options are brought to the test by the Austrian ABCSG-12 study [24], comparing an LHRH analogue in concert with either tamoxifen or anastrozole in the adjuvant setting. With a median follow-up time of 60 months, there is no difference between the 2 arms with respect to relapse rate. Most interestingly, the same study also randomized patients to $+/-$ zoledronic acid $4 \mathrm{mg}$ intravenously every 6 months, providing a $2 \times 2$ arm design. Use of zoledronic acid reduced the relapse rate by $35 \%$ compared to placebo across the 2 treatment options (anastrozole and tamoxifen). If confirmed in ongoing trials and during long-term follow-up, these results may have profound impact on our clinical practice. Even more, it represents a highly innovative approach pointing to a new direction for optimal combined treatment. Important issues arise; would a similar effect be recorded for example with use of the novel RANK(L) inhibitors? There may be theoretical arguments in favor [25].

\section{Conclusion}

So, what should be the future impact of molecular biology on therapy selection? Are we to expect novel targeted therapy to take over treatment, leaving 'old-fashioned' treatment options as endocrine therapy behind? Use of trastuzumab in the adjuvant setting turned out to be a great success [26]. Yet, we should recognize there are two major cell growth driving pathways in breast cancer; the HER-2 pathway being active in about $25 \%$ of tumors, and the ER pathway. Little evidence so far suggests any additional pathways of vital importance to cellular growth to be discovered in the future. Molecular biology is not likely to leave endocrine therapy redundant; rather, it may extend and improve our understanding of the mechanisms of action as well as resistance to these treatment manipulations. As such, we will learn more with respect to the potential of combining endocrine and targeted therapy. Perhaps more importantly, we may achieve better knowledge to improve use of endocrine therapy by its own.

\section{References}

1 Group EBCTC: Tamoxifen for early breast cancer: an overview of the randomised trials. Lancet 1998; 351:1451-67.

2 Early Breast Cancer Trialists' Collaborative Group: Ovarian ablation in early breast cancer: overview of the randomised trials. Lancet 1996;348:1189-96.

-3 Mouridsen H, Gershanovick M, Sun Y, Perez-Carrion R, Boni C, Monnier A, et al.: Phase III study of letrozole versus tamoxifen as first-line therapy of advanced breast cancer in postmenopausal women analysis of survival and update of efficacy from the international letrozole breast cancer group. J Clin Oncol 2003;21:2101-9.
\4 Baum M, Buzdar AU, Cuzick J, Forbes J, Houghton J, Klijn JGM, et al.: Anastrozole alone or in combination with tamoxifen versus tamoxifen alone for adjuvant treatment of postmenopausal women with early breast cancer: first results of the ATAC randomised trial. Lancet 2002;359:2131-9.

5 Jakesz R, Jonat W, Gnant M, Mittlboeck M, Greil $\mathrm{R}$, Tausch C, et al.: Switching of postmenopausal women with endocrine-responsive early breast cancer to anastrozole after 2 years' adjuvant tamoxifen: combined results of ABCSG trial 8 and ARNO 95 trial. Lancet 2005;366:455-62.
6 Goss PE, Ingle JN, Martino S, Robert NJ, Muss HB, Piccart MJ, et al.: A randomized trial of letrozole in postmenopausal women after five years of tamoxifen therapy for early-stage breast cancer. N Engl J Med 2003;349:1793-802.

7 Thurlimann B, Keshaviah A, Coates AS, Mouridsen $\mathrm{H}$, Mauriac L, Forbes JF, et al.: A comparison of letrozole and tamoxifen in postmenopausal women with early breast cancer. N Engl J Med 2005;353: 2747-57.

8 Coombes RC, Hall E, Gibson LJ, Paridaens R, Jassem J, Delozier T, et al.: A randomized trial of exemestane after two to three years of tamoxifen therapy in postmenopausal women with primary breast cancer. N Engl J Med 2004;350:1081-92. 
-9 Jakesz R, Hausmaninger H, Kubista E, Gnant M, Menzel C, Bauernhofer T, et al.: Randomized adjuvant trial of tamoxifen and goserelin versus cyclophosphamide, methotrexate, and fluorouracil: evidence for the superiority of treatment with endocrine blockade in premenopausal patients with hormone-responsive breast cancer - Austrian Breast and Colorectal Cancer Study Group Trial 5. J Clin Oncol 2002;20:4621-7.

10 Jonat W, Kaufmann M, Sauerbrei W, Blamey R, Cuzick J, Namer M, et al.: Goserelin versus cyclophosphamide, methotrexate, and fluorouracil as adjuvant therapy in premenopausal patients with node-positive breast cancer: the Zoladex Early Breast Cancer Research Association Study. J Clin Oncol 2002;20:4628-35.

11 Klijn JGM, Beex LVAM, Mauriac L, van Zijl JA, Veyret C, Wildiers J, et al.: Combined treatment with buserelin and tamoxifen in premenopausal metastatic breast cancer: a randomized study. J Natl Cancer Inst 2000;92:903-11.

12 Klijn JGM, Blamey RW, Boccardo F, Tominaga T, Duchateau L, Sylvester R: Combined tamoxifen and luteinizing hormone-releasing hormone (LHRH) agonist versus LHRH agonist alone in premenopausal advanced breast cancer: a metaanalysis of four randomized trials. J Clin Oncol 2001;19:343-53.
13 Arpino G, Wiechmann L, Osborne CK, Schiff R: Crosstalk between the estrogen receptor and the HER tyrosine kinase receptor family: molecular mechanism and clinical implications for endocrine therapy resistance. Endocr Rev 2008;29:217-33.

14 Shou J, Massarweh S, Osborne CK, Wakeling AE, Ali S, Weiss H, et al.: Mechanisms of tamoxifen resistance: increased estrogen receptor-HER2/neu cross-talk in ER/HER2-positive breast cancer. J Natl Cancer Inst 2004;96:926-35.

15 Kaufman B, Mackey J, Clemens M, Bapsy P, Vaid A, Wardley A, et al.: Trastuzumab plus anastrozole prolongs progression-free survival in postmenopausal women with HER-2positive, hormonedependent metastatic breast cancer (MBC). Ann Oncol 2006;17(suppl 9).

16 Smith IE, Walsh G, Skene A, Llombart A, Mayordomo JI, Detre S, et al.: A phase II placebo-controlled trial of neoadjuvant anastrozole alone or with gefitinib in early breast cancer. J Clin Oncol 2007;25:3816-22.

17 Masamura S, Santner SJ, Heitjan DF, Santen RJ: Estrogen deprivation causes estradiol hypersensitivity in human breast cancer cells. J Clin Endocrinol Metable 1995;80:2918-25.

18 Lippman M, Bolan G, Huff K: The effects of estrogens and antiestrogens on hormone-responsive human breast cancer in long-term tissue culture. Cancer Res 1976;36:4595-601.

19 Haddow A, Watkinson JM, Paterson E: Influence of synthetic oestrogens upon advanced malignant disease. Brit Med J 1944;2:393-8.
20 Ingle JN, Ahmann DL, Green SJ, Edmonson JH Bisel HF, Kvols LK, et al.: Randomized clinical trial of diethylstilbestrol versus tamoxifen in postmenopausal women with advanced breast cancer. N Engl J Med 1981;304:16-21.

21 Lønning PE, Taylor PD, Anker G, Iddon J, Wie L, Jorgensen LM, et al.: High-dose estrogen treatment in postmenopausal breast cancer patients heavily exposed to endocrine therapy. Breast Cancer Res Treat 2001;67:111-6.

22 Lønning P: Strength and weakness of phase I-IV trials with emphasis on translational aspects. Breast Cancer Res 2008. In press.

23 Lønning PE: Aromatase inhibitors in breast cancer. End Rel Cancer 2004;11:179-89.

24 Gnant M, Mineritsch B, Schippinger W, LuschinEbengreuth G, Poestlberger S, Menzel C, et al.: Adjuvant ovarian suppression combined with tamoxifen or anastrozole, alone or in combination with zoledronic acid, in premenopausal women with hormone-responsive stage I and II breast cancer: first efficacy results from ABCSG-12. J Clin Oncol 2008;26(suppl 18 II):LBA4, 1006s.

25 Lønning PE: Endocrine therapy and bone loss in breast cancer: time to close in the RANK(L)? J Clin Oncol 2008;26:4859-61.

26 Romond EH, Perez EA, Bryant J, Suman VJ, Geyer CE Jr, Davidson NE, et al.: Trastuzumab plus adjuvant chemotherapy for operable HER2-positive breast cancer. N Engl J Med 2005;353:1673-84. 